\title{
Calcification in the Soft Tissues of the Chest after Thoracotomy
}

\author{
S.J. White, M.D., and R.J. Hernandez, M.D. \\ Department of Radiology, The University of Michigan Medical Center, Ann Arbor, Michigan, USA
}

\begin{abstract}
We have observed soft-tissue calcification of the chest in 4 of 54 patients following thoracotomy in the neonatal period for a Blalock-Taussig or a Blalock-Hanlon procedure. The time of appearance ranged from 2 weeks to 11 months. This calcification is similar to myositis ossificans in having a traumatic origin. In one of the patients, it resolved spontaneously.
\end{abstract}

Key words: Calcification - Postsurgical changes Chest wall.

A number of postoperative changes in the radiographic appearance of the chest have been described [2,3]. To our knowledge, the presence of chest wall calcification postoperatively has not been previously noted. This paper describes the occurrence and incidence of chest wall calcification following thoracotomy.

\section{Subjects}

The chest radiographs of children who had BlalockTaussig or Blalock-Hanlon procedures done between July 1975 and September 1978 at the University of Michigan Medical Center were reviewed. They represent 54 consecutive procedures. The patients were operated on average within the first month of life. The chest radiographs were reviewed looking specifically for the presence of soft-tissue calcification.

Address reprint requests to: Ramiro Hernandez, M.D., Department of Radiology, Children's Memorial Hospital, 2300 Children's Plaza, Chicago, IL 60614, USA

\section{Results}

Of the 54 patients, four showed calcification in the soft tissues of the chest wall at the site of chest tube insertion. The calcific density varied from a large and densely calcified density in one patient (Fig. 1) to a smaller and partially calcified density in the other three patients (Fig. 2).

One patient had serial radiographs showing progressive resolution with a normal appearance two years postoperatively. Of the three other patients, one
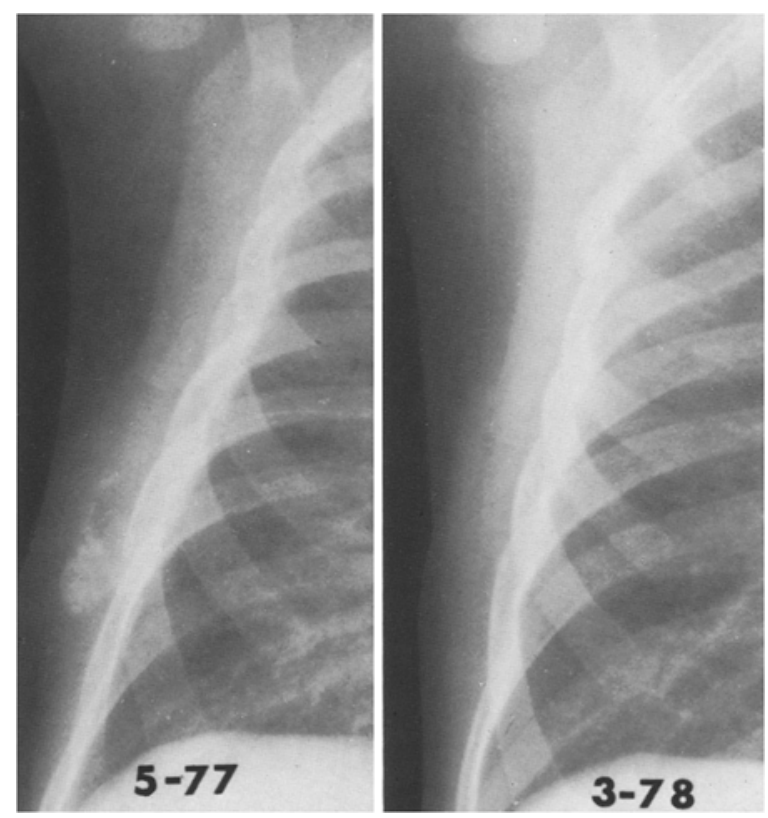

Fig. 1. Soft-tissue calcification in a patient with transposition of the great arteries who had a Blalock-Hanlon procedure nine months before this radiograph was obtained. Follow-up film obtained 10 months later shows resolution of the calcific density 


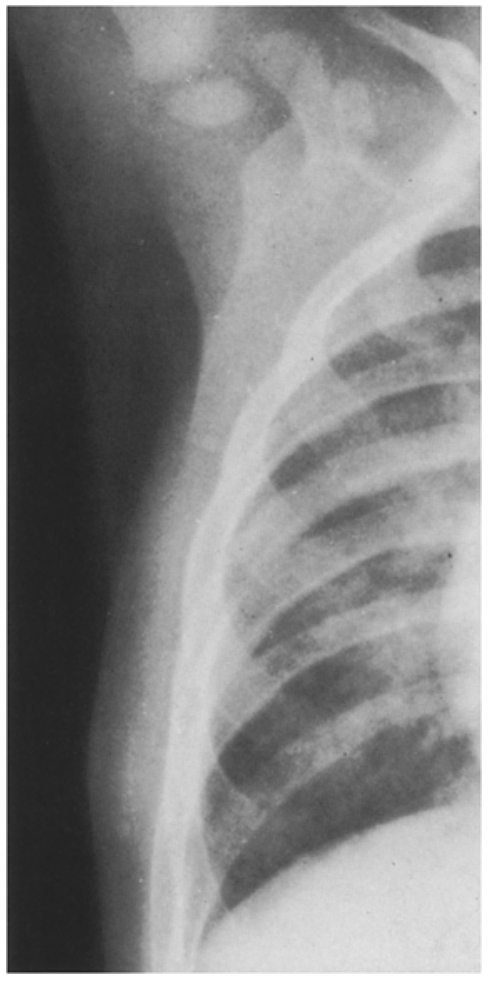

Fig. 2. Faint calcification in the soft tissues seven months following a Blalock-Hanlon procedure

died, one was lost to follow-up, and the third still had calcification remaining 15 months after surgery. The earliest calcification was seen two weeks after surgery, while the others appeared at approximately 2 months and 11 months after operation (although the last patient had a hiatus after surgery when no radiographs were taken).

\section{Discussion}

The presence of soft-tissue calcification is presumed to be related to surgical trauma, just as myositis ossificans is related to incidental trauma. The evolution of the calcific mass in these four patients is similar to the radiographic evolution described in myositis ossificans $[4,5]$ : Soft-tissue edema first appears, then cloudy calcification progressing to more dense calcification, and finally decrease in size of the calcific mass or disappearance. However, while myositis ossificans is described as having a dense periphery and lucent center, the calcification in our patients was more amorphous. We describe chest wall calcification following thoracotomy so that it may be recognized as a benign finding. Proper management would seem to be observation and anticipation of its eventual resorption. It is to be distinguished from extraskeletal osteochondromatosis. Another cause of soft-tissue calcification is extravasation of calcium gluconate [1] at the site of an intravenous injection. Malignant possibilities, such as extraskeletal osteosarcoma, are considered so rare as to be practically excluded.

\section{References}

1. Berger, P.E., Heidelberger, K.P., Poznanski, A.K.: Extravasation of calcium gluconate as a cause of soft tissue calcification in infancy. Am. J. Roentgenol. 121, 109 (1974)

2. Curry, G.C., Victorica, B.E., Daicoff, G.R., Elliott, L.P.: Radiologic changes following repair and palliation of right-to-left and admixture shunts. Radiol. Clin. North Am. 9, 177 (1971)

3. McCormick, T.L., Kuhns, L.R., Perry, B.L.: Radiographic changes in children following cardiac surgery performed by splitting the sternum. Radiology 118, 141 (1976)

4. Norman, A., Dorfman, H.D.: Juxtacortical circumscribed myositis ossificans: Evolution and radiographic features. Radiology 96, 301 (1970)

5. Ozonoff, M.B.: Pediatric orthopedic radiology, pp. 423427. New York: Saunders 1979 